a lumbar incision parallel with the Jast rib, was performed by Dr. Maurice H. Richardson. 'The kidney was seen to be of norinal appearance, and palpation failed to reveal calculus. The kidney was sutured to the abdominal wound by six silkworm sutures passed through the fibrous capsule of the kidney, but not through the substance of the organ. The capsule was not split. The abdominal wound was closed by silkworm sutures. It united by first intention.

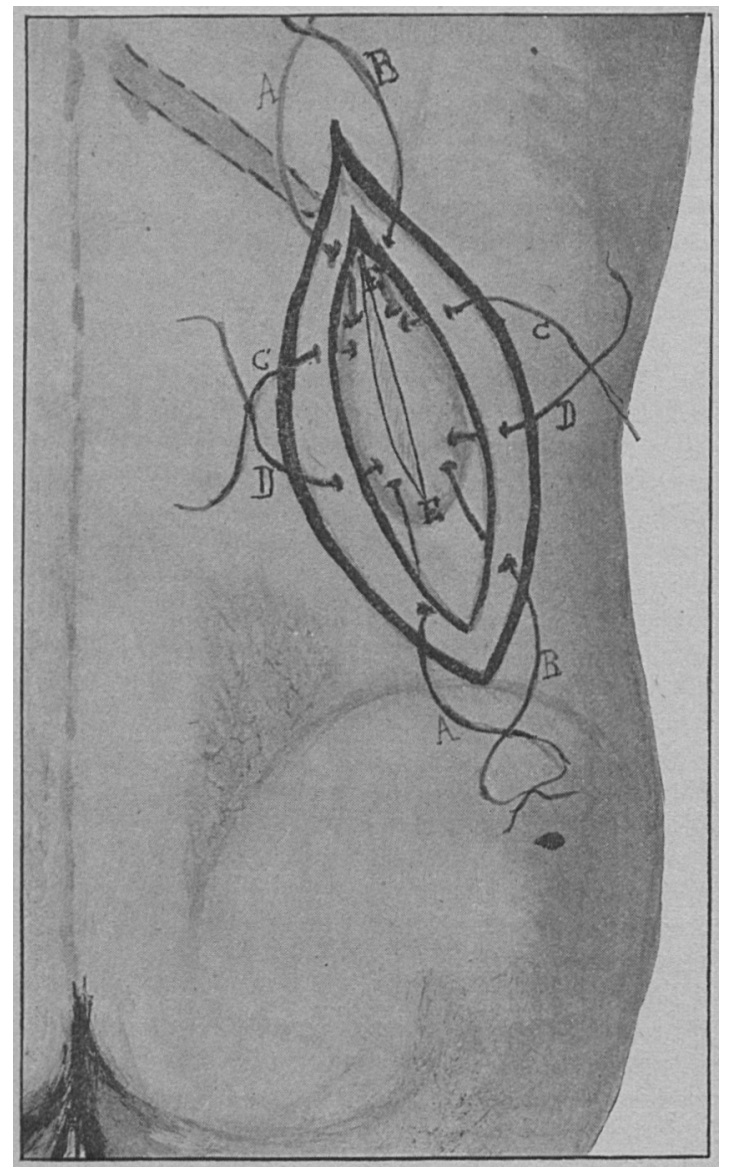

A A, B B, Longitudinal sutures passing through lumbar muscles, capsule and cortex of kidney.

C C, D D. 'Transverse sutures passing through the same structures. $A$ and $B$, and $C$ and $D$, are tied together at either end, thus slingin the kidney as in a hammock and apposing the muscular incision. E E, Longitudinal slit in capsule.

During the first six days the patient suffered a degree of pain such as I have never seen follow any surgical operation. The urine diminished in quantity during this time, and it was feared to give large doses of morphia such as would have been required to stop the pain. She had, however, subcutaneous doses of one-quarter of a grain three or four times in the twenty-four hours, but these were almost without effect. The only relief to the pain was found in the sitting posture, and the patient could not be kept on her back in consequence. It was on this account, $I$ think, that the kidney became detached again.

On the sixth day the patient said that she was sure that the kidney had dropped down; the pain suddenly ceased, which seemed confirmatory, although at the time there was not much importance attributed to what the patient said. It was subsequently found to be true, for at the end of a month the kidney could be plainly felt again in its abnormal position in the abdomen.

The pain returned in this kidney, but was at no time so severe as before the operation. The pain in the right kidney became very severe, and almost constant, and attacks of intermittent hydronephrosis were well marked and frequent.

Nephrorraphy with a new method of applying the sutures. - An incision was made along the border of the quadratus. There was very little perineal fat. The kidney was slightly enlarged, but otherwise seemed to be normal.

The posterior border of the kidney was freed from its fat capsule. Two chromicized catgut sutures were then passed through the fibrous capsule and the kidney substance, through two-thirds of the length of the organ, parallel to each other and about half an inch apart on either side of the posterior border of the kidney. These sutures were passed through the edges of the muscular layer of the lumbar wound. 'Two cross sutures were then carried through the kidney close to the points of entrance and exit of the long stitches. This method of applying the sutures is illustrated in Fig. 1. The object of so placing them is to sling the kidney as in a hammock, in order to secure the longest line of bearing for them and the least amount of cutting action, the cross sutures being placed as an extra security to prevent the tearing out of the long ones by placing an obstacle across their path should they do so.

Attention is called to the way in which the sutures are tied together, for on that depends their acting as a sling or hammock, and the avoidance of their cutting out. Before tying them and closing the lumbar wound, the fibrous capsule was split between the two long sutures over nearly the whole length of the kiduey.

The fat capsule was cut away on either side of the convex border of the kidney, as recommended by Edebobls, the four kidney sutures were tied, and the lumbar wound closed by two layers of catgut sutures, one for the muscular, and one for the skin wound.

There was much less pain following this operation than the first, although the patient suffered much for the first four or five days. The pain was, however, bearable in the recumbent posture.

Three months and a half bave passed since the operation. The patient has gained eight pounds in weight; there has been no pain in the right kidney since the first three weeks; and for the last six weeks pain has ceased in the left kidney also.

\section{A CASE OF ACROMEGALY TREATED WITH THYROID EXTRACT.}

BY G. G. SEARS, M.D.,

Assistant Visiting Physician, Boston City Hospital.

Mrs. C., a widow, forty-five years old, first presented herself for treatment at the Boston City Hospital in Jauuary, 1895. Her materual grandfather died insane; her father of a "complication of diseases," probably of cardiac origin, at the age of fifty; her mother of apoplexy at seventy-one. She has lost two brothers from consumption, while one brother, when last seen several years ago, had a brownish discoloration of the skin similar to that of the patient herself, and was "all bloated up." 
She has had three children, none of the labors being noteworthy, one of whom died of cholera infantum, the other two are well but not strong.

Her previous medical history consists of an attack of varioloid, when eight years old, erysipelas when eighteen, and pneumonia when twenty. Five years ago she had an attack of grippe accompanied by severe pain in her left ear. She has had occasional attacks of cholera morbus, and has been under treatment for retroversion of the uterus and a lacerated cervix. She reached the menopause about six months ago, but had been irregular for about a year. Her general health has always been good, but she has complained all her life of drowsiness, which in recent years has so increased that now she is liable to drop asleep at any time. With this exception sho dates all of her symptoms from twelve years ago, when a flatirou fell upon her left side, starting up a brisk uterine hemorrhage, which lasted, however, but a short time. 'The nervous shock was much greater than the physical injury, and after this she passed large quantities of urine and had attacks of sudden weakness, in which she fell but yet retaiued consciousness. She began also to be very susceptible to cold, so that she had to wear extra flanuels and take hot-water bottles to bed with her even in summer. Lately this symptom has grown decidedly better, and she now complains chiefly of local chilly feelings with the appearance of "gooseflesh" in spots about as large as a five-cent piece. Soon after the accident she noticed that her hands and feet were increasing in size, so that while she once wore a $3 \frac{1}{2}$ shoe she now requires a broad 7 , and instead of a $6 \frac{1}{2}$ glove she now wears a $7 \frac{1}{2}$, while her tongue has become so large that it is frequently bitten and at times "feels so big that she wonders whether or not she can thrust it out of her mouth." Her face grew fuller, her nose more prominent and her hair coarser and drier, but it has never fallen out and still haugs nearly to her knees. She has suffered intensely at times, especially at night after sweeping or washing, from a feeling of numbness in her hands, which is accompanied by itching, pain and a sensation of pins and needles. Her body also has at times felt 8 sre and tender all over and on lying down her joints become so rigid that she moves with difficulty, while on rising her knees are so stiff that the first few steps are bard to take. She has had frequent attacks of cardiac palpitation as well as very distressing hot flashes recurring every ten or fifteen minutes. Sweating, especially at night, and most noticeably over the chest, has also been a fairly constant symptom. Every little while she hears a "puffing" in her ears synchronous with the heart and lasting for a longer or shorter period, but which for a day at a time may be nearly constant. About five years ago she lost her husband after a very loug and trying illness, and after this she noticed that her mental processes seemed slow and that her memory was greatly impaired, so that she would often begin a sentence and then forget what she was about to say. She also became unusually nervous and irritable over trifles. A month ago her nose was cleared of mucous polypi by Dr. Leland, but they have now returned. Her appetite has been ravenous and her thirst excessive.

The patient is a rather heavily-built woman about five feet five inches tall and weighing 175 pounds. She stands fairly erect without the marked kyphosis which has been noticed in many of these cases. Her face appears somewhat lengthened, and tho frontal aspect of the heal is triangular in shape from an enlargement of the jaws, especially the lower, the under teeth closing a littlo outside the upper. 'There is no elevation of the eyebrows, but the eyelids appear. puffy, and the skin of the face is thickened and wasklike. The nose is noticeably large, the enlargement being in both the soft parts and tho bones.

The hair of the head, as well as of the pubes and axilla, is coarso and dry, but very abundant and only slightly streaked with gray. 'Tho teeth are in good condition, but there is some retraction of the gums. 'The tongue is enlarged to at least a half more than its normal size. Over considerable areas on the neck and face the skin, which is everywhere moist, is brown in color, and similar patches of discoloration are seen over the trunk and limbs.

Scattered over the neck and trunk are very numerous small growths varying in size from the head of a pin to that of a bean, some of which are deeply pigmented. A few are pedunculated but most are sessile. There is no marked fulness above the clavicles.

The clavicles themselves are not noticeably enlarged, but the mauubrium seems heavier and thicker than normul, while the angle at its juncture with the second piece of the sternum is more than usually acute. Over the manubrium the percussion note is somewhat dull, the probable result of the increased thickness of the bone.

The ribs seem heavier and are somewhat closer to each other than they should be. Owing to the thick fat layer it is difficult to determine changes in the ilia, but they seem to have become thicker aud heavier. 'There is a very marked enlargement of the hands, especially in their breadth and thickness, which is due less to changes in the bones than in the soft part covering them. The fiugers are thick and stubby; the nails are short, broad and marked with longitudi. nal striations. 'The crescent is covered.

The feet show similar alterations, but in them an enlargement of the bones is more readily made out, the toes appearing decidedly longer than normal. 'The aukles and lower part of the legs are pulfy and pit deeply on pressure. The chest is fairly-well shaped and measures at the two respiratory extremes 32 and $34 \frac{1}{2}$ iuches. Except for a prolongation of the expiratory sound, which can be accounted for by a loss of elasticity of the chest walls, examination of the lungs is negative. The area of cardiac dulness is slightly enlarged laterally, but except for their rapidity and weakness there is no modification of the sounds.

The voice is thick, monotonous and plaintive, while words are very slowly enunciated. All musculur movements are slow and weak, while the tenderness of the hands is so great that she is unable to grasp the dynamometer with sufficient force to move the index. Pulse 128. Temperature $100^{\circ} \mathrm{F}$.

'The following measurements of the head, hands and feet may be of interest. The patient is left-handed.

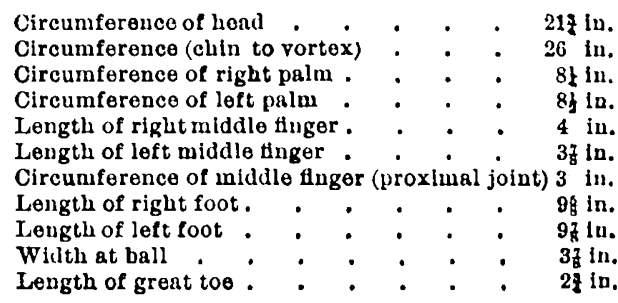


The enlargement of the hands and feet, however, is more conclusively shown by the larger sizes of gloves and shoes which she now requires than by these measurements.

For the examination of the special senses as well as for the electrical tests, I am indebted to Dr. P.C. Knapp, who went over the case with much care. Smell is nearly lost, there being no perception of camphor or meuthol with the right nostril and only slight with the left, a condition probably explained by the presence of polypi. Vision is practically normal, the field is not contracted and the color seuse is good. Nothing abnormal was seen in the fundus oculi. Hearing in the right ear is normal, but with the left ear a watch caunot be heard more than six inches away. Taste, cutaneous sensibility and the muscle sense are unimpaired.

The electrical reactions are considerably diminished quantitatively to galvanism and slightly to faradism, but there are no qualitative changes.

'The urine had a specific gravity of 1.018 and contained neither sugar nor albumin; the daily amount was slightly in excess of the normal quantity.

She was put on general tonics and on the dried extract of thyroid gland in gradually-increasing doses until 12 grains a day were taken, while galvanism was for a time given by Dr. Knapp.

On the 17th of April, three months after her first visit, she reported that she was feeling very much better and took more interest in current events. Her memory bad improved and she spoke and moved more rapidly. Pain in the hands had greatly diminished, so that she slept well at night, but her joints still felt stiff. Her grasp was firm, and she was able to do her own washing and irouing, even to wringing out the clothes with her hands. "The "puffing" in her ears was gone and the palpitation of the heart better. 'There was much less putfiness about the eyes and no pitting over the aukles. She had lost over twenty pounds in weight, but felt stronger than for many months.

From this time to the present her geueral condition has remained practically the same or possibly has slightly improved. She has been able to do all her own housework, even to the sewing, and has also gone out on one or two occasions in the capacity of monthly nurse. Her mental condition is normal except that she complains that her memory is still somewhat defective. Her weight is still further reduced so that she now tips the scales at 146 pounds, but there bas been no change in the measurements of her hands or feet. The lougitudinal furrows on her nails are, however, less marked and her tongue shows a considerable diminution in size. The mucous growths in the nose have disappeared and the nasal passages are unobstructed. During last June she suffered for a time from very severe vertical headaches and she has had occasional attacks of palpitation and vomiting, which were apparently due to an overdose of thyroid extract, which she has taken almost continuously in daily amounts varying from three to nine grains. The temperature, wbich twas taken only at infrequent intervals, ranged from $98.5^{\circ}$ to $99.2^{\circ}$, more commonly the latter.

The history of the case and the marked physical changes leave little doubt that we were dealing with a case of acromegaly, but certain anomalous symptoms, such as the puffy conditions of the eyelids, which may however, have been simply the result of anemia, though its appearance was somewhat different, the slow speech and the altered mental state suggested that her condition was also associated with a loss of function of the thyroid gland, which was strengthened by the fact that it could not be felt even after she had lost considerable flesh, and the decided improvement following the administration of thyroid extract. 'The direct effects of treatment were seemingly apparent in the loss of weight, the diminished trophic disturbance of the nails, the decreased size of the tongue, the disappearance of the mucous growths in the nose, and perhaps also, if Schaefer's observation is correct, that the thyroid secretion dilates the blood-vessels, in the cessation of pain in the hands; but in the latter case it is somewhat doubtful how far this result was due to the action of the remedy and how far to the diminishing influence of the climacteric which she had recently passed and which may have been a more or less potent factor in causing pain from the vasomotor disturbances incidental to it. 'The other treatment employed consisted of touics and the careful regulation, so far as possible, of her diet aud general hygiene.

Regarding the etiology of the case, the condition of her brother, as she describes it, is interesting as show. ing a possible family taint, which has not been observed in any of the reported instances; but the facts are too meagre on which to base even a probable diagnosis, and as be lives many miles away no more definite information could be obtained. In her own history no adequate cause could be found. It is true that she dates her symptoms from the time when she was struck with a flat-iron, but the nervous shock which this produced simply called her attention to a coudition which had imperceptibly come on, as a photograph taken some months at least before the accident, shows that quite marked changes had already taken place.

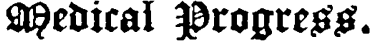

\section{REPORT ON DISEASES OF CHILDREN.}

BY T. M. ROTCH, M.D., AND A. H. WENTwORTH, M.D.

\section{DIABETES MELLITCS IN CHILDHOOD.}

THE author collected 108 cases from the literature which was tabulated. A review of the table shows that 48 of the patients were females, 47 were males, and of the remuining 13 the sex was not stated. In six of the cases, the age was not given. Three were under one year; 26 between one and five years; 31 between five and ten years, and 42 between ten and sixteen years. Traumatism was supposed to be the cause in 11 cases; unfavorable hygienic surroundings in seven; severe illness in four; difficult dentition in two; taking of cold in two, and over-exertion in two. Poverty, fright, worry, convulsions, are all considered to be causes. Heredity and a neurotic family history play an important rôle in the etiology. In 12 cases the parents or near relatives had diabetes. In two cases the father had syphilis.

The symptoms in children are very similar to those met with in adults. The amount of urine passed in twenty-four hours, as a rule, ranged from one and one-half to fourteen pints. In two cases the amount was ten quarts. One of these was a fourteen-year-

1 Wegeli : Archiv. f. kinderheilkunde, 1895 . B. xix, H. 1, 2; Archives of Pediatrice, February, 1896. 